Bull. Chem. Soc. Ethiop. 2020, 34(2), 407-418.

ISSN 1011-3924

(C) 2020 Chemical Society of Ethiopia and The Authors

Printed in Ethiopia

DOI: https://dx.doi.org/10.4314/bcse.v34i2.16

\title{
METOLAZONE COMPOUND AS CORROSION INHIBITOR FOR API 5L X-52 STEEL IN HYDROCHLORIC ACID SOLUTION
}

\author{
Fidelis E. Abeng ${ }^{1 *}$, Magdalene E. Ikpi ${ }^{2}$, Valentine C. Anadebe ${ }^{3}$ and Wilfred Emori ${ }^{4}$ \\ ${ }^{1}$ Material and Electrochemistry Research Unit, Department of Chemistry, Cross River \\ University of Technology, P. M. B. 1123, Calabar-Nigeria \\ ${ }^{2}$ Corrosion and Electrochemistry Research Laboratory, Department of Pure and Applied \\ Chemistry, University of Calabar, P.M.B. 1115, Calabar-Nigeria \\ ${ }^{3}$ Department of Chemical Engineering, Federal University Ndufu Alike, Ebonyi state, P. M. B. \\ 1010, Abakaliki, Nigeria \\ ${ }^{4}$ School of Materials Science and Engineering, Zigong 643000, Sichuan, China
}

(Received May 20, 2019; Revised September 28, 2020; Accepted September 29, 2020)

\begin{abstract}
The aim of this research is to evaluate the inhibitive effect of metolazone on API 5L X-52 steel in $2 \mathrm{M} \mathrm{HCl}$ solution using electrochemical impedance spectroscopy (EIS), potentiodynamic polarization techniques within a temperature range of 303 to $323 \mathrm{~K}$. Scanning electron microscopy (SEM) was also employed to study the morphology of the corroded coupons in $2 \mathrm{M} \mathrm{HCl}$ solution and in the presence of the inhibitor. The efficiency of the inhibition depends on the concentration of metolazone and reaction system temperature. The maximum inhibition efficiency values were 92.7 and $90.7 \%$, respectively, for both EIS and polarization techniques at the temperature of $303 \mathrm{~K}$. The electrochemical impedance spectra (EIS) studies reveal that the process of inhibition is through charge transfer. Potentiodynamic polarization (PDP) studies showed that metolazone is mixed-type inhibitor. The metolazone adsorption characteristics on API 5L X-52 steel surface was found to be spontaneous and obeyed Langmuir adsorption isotherm and the mechanism of adsorption suggest chemisorptions. The inhibition efficiency of metolazone drug obtained by electrochemical methods was in good relationship with each other.
\end{abstract}

KEY WORDS: Metolazone drug, API 5L X-52 Steel, SEM, Electrochemical, Corrosion inhibition

\section{INTRODUCTION}

The application of metals and alloys are of great interest in industrial installations and equipment. Metals and alloys are generally attacked by aggressive fluids, either by natural fluids or artificial fluids [1]. This occurrence may cause damages to metal surface as well as loss of cohesive strength. The structure of the metal surface is attacked through the movement of ions away from the surface of the metal leading to the corrosion of metals [1]. In the industrial field, carbon steel is a type of material that is commonly used for various applications. One of those types of carbon steel which is often used in the industrial field is API 5L steel grade. The API $5 \mathrm{~L}$ steel is one of the steels used in the applications of water transport, oil, and natural gas. One of the problems that often occur in the distribution process of crude oil is the existence of sediment called the crust (scale). The crust is the result of mineral precipitation which is derived from the water formation produced along with the oil and gas [2]. This type of steel is easy to be corroded in acidic environment. In fact, corrosion cannot be prevented but its speed can be controlled by the addition of an inhibitor. The use of corrosion inhibitor is one of the practical ways of preventing the movement of ions away from the surface of the metals. Corrosion inhibitor is simply define as chemical substances that when added in a small concentration to corrosive environment where metals and alloys reside decreases the rate of attack on the metal surface. These chemical substances may be costly and not friendly. The present study employs

*Corresponding author. E-mail: fidelisabeng@yahoo.com

This work is licensed under the Creative Commons Attribution 4.0 International License 
the use of economical and environmentally friendly corrosion inhibitor such as metolazone drug-based compound to prevent the formation of corrosion at a metal surface. The effectiveness of metolazone compound as inhibitor essentially depends on the presence of functional groups or atoms like N, O, S, P and $\pi$ electron in their moiety [2-4]. In view of the above observation it is thought worthwhile to study the corrosion inhibition behavior of metolazone drug as a corrosion inhibitor for carbon steel in acidic medium using electrochemical impedance spectroscopy, potentiodynamic polarization methods and scanning electron microscope. Metolazone is a thiaziole like diuretic marketed under the brand name, zytanix. It is primarily used for the treatment of congestive heart failure and high blood pressure. The IUPAC name of metolazone is chloro-2-methyl-4-oxo-3-O-tolyl-1,2,3,4tetrahydroquinazoline-6-sulfonamide with molecular formula and molecular mass of $\mathrm{C}_{16} \mathrm{H}_{16} \mathrm{Cl}$ $\mathrm{N}_{3} \mathrm{O}_{3} \mathrm{~S}$ and $365.835 \mathrm{~g} / \mathrm{mol}$, respectively. The chemical structure of metolazone is given in Figure 1. Recent studies have shown that pharmaceutical drugs can also increase the anticorrosion performance of metals or alloys. Extensive research have been conducted on the use of azole drugs namely fluconazole, ketoconazole and cotrimazole on the corrosion inhibition of mild steel in aqueous solution of chloride ions using weight loss, AC impedance spectra and polarization study, the results obtained from the studied compounds exhibited good corrosion inhibition properties for which it depends on the inhibitor concentration [5-8].

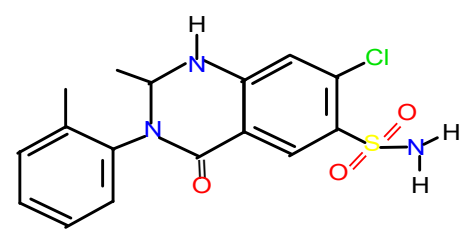

Figure 1. Molecular structure of metolazone.

Ade et al. [9] reported on the inhibitive action of an antibiotic drug as corrosion inhibitor for mild steel in $\mathrm{HCl}, \mathrm{HNO}_{3}$ and $\mathrm{H}_{2} \mathrm{SO}_{4}$ solutions using weight loss. The results obtained from the studied acids revealed that the compound inhibited the metal dissolution by 92,83 and $91 \%$, respectively. The adsorption of the inhibitor obeyed the Langmuir adsorption isotherm. Karthikeyan et al. [10] used weight loss, potentiodynamic polarization, and electrochemical impedance spectroscopy and hydrogen permeation measurements to investigate vancomycin as a corrosion inhibitor for mild steel in a $1 \mathrm{M} \mathrm{H}_{2} \mathrm{SO}_{4}$ solution. The results obtained in their study showed that inhibition efficiency depends on the concentration of vancomycin. Potentiodynamic polarization study revealed that the inhibitor functioned as a cathodic inhibitor and that inhibitor adsorption on a mild steel surface followed Langmuir adsorption model. Abdullatef [11] used potentiodynamic polarization and electrochemical impedance spectroscopy to study azithromycin's inhibitory activity as an inhibitor for the corrosion of mild steel, copper and zinc in a solution of $0.5 \mathrm{M} \mathrm{H}_{2} \mathrm{SO}_{4}$. The results obtained shows that azithromycin inhibited the corrosion of all the metals used. The inhibitor's adsorption on the steel, copper, and zinc surface obeyed the Langmuir isotherm adsorption. Potentiodynamic polarization results indicated that azithromycin acted as a mixed type inhibitor for mild steel and as a cathodic type in zinc and copper. Among the various drugs used, metolazone which is one of the most promising pharmaceutical drug in recent times have not been reported. 


\section{EXPERIMENTAL}

\section{Materials and inhibitor preparation}

The test sample used in corrosion studies were cut from a piece of API 5L X-52 pipeline steel (carbon steel), with the composition of Fe $(98.28 \%), \mathrm{C}(0.24 \%), \mathrm{Mn}(1.40 \%), \mathrm{P}(0.05 \%), \mathrm{S}$ $(0.015 \%), \mathrm{Si}(0.45 \%), \mathrm{V}(0.01 \%), \mathrm{Nb}(0.05 \%)$ and $\mathrm{Ti}(0.04 \%)$ [12]. Prior to the experiment, all the samples were consequently abraded with 220,800 and 1200 emery grade paper to have a mirror like surface using a UNIPOL-820 metallographic polishing machine. Thereafter, the sample of the specimen was rinsed with ethanol, decreased by acetone and dried in warm air. The metolazone compound was supplied by Peace Land Pharmaceutical Ltd, Calabar-Nigeria. The concentration of the inhibitor stock solution was prepared by digesting $500 \mathrm{mg}$ of the drug compound in $1000 \mathrm{~mL}$ of $2 \mathrm{M} \mathrm{HCl}$ solution to obtain a stock solution of $500 \mathrm{mg} / \mathrm{L}$ concentration. The resulting solution was allowed to stand for 24 hours to enhanced proper solubility of the drug compound. Different concentrations of the inhibitor test solution were calculated from the stock solution using the dilution factor; $\mathrm{C}_{1} \mathrm{~V}_{1}=\mathrm{C}_{2} \mathrm{~V}_{2}$ and used subsequently in the electrochemical measurements.

\section{Electrochemical measurements}

Gamry Reference 600 Potentiostat/Galvanostat inclusive of Gamry framework EIS 300 and DC 105 system was used to perform electrochemical measurement. The electrochemical measurement device consists of a platinum wire as counter electrode, a saturated calomel electrode (SCE) as reference electrode and the API 5 L X-52 pipeline steel specimens as a working electrode (WE). The working electrode has surface area of $1 \mathrm{~cm}^{2}$ and Gamry Echem Analyst software was used in analyzing the experimental data. Potentiodynamic polarization curves were obtained by applying potential at a scan rate of $0.5 \mathrm{mVs}^{-1}$ over the range $-250 \mathrm{mV}$ to $+250 \mathrm{mV}$. Electrochemical impedance Spectroscopy measurements were performed in a frequency range of $100 \mathrm{KHz}$ to $10 \mathrm{MHz}$ with a $5 \mathrm{mV}$ AC signal amplitude under potentiostatic conditions. An immersion period of 30 minutes was employed before the test to attain steady state potential [13].

\section{Steel surface characterization}

After the specimen was taken out and cleaned, the API 5L X-52 pipeline steel (carbon steel) specimens were soaked in different test solution for 24 hours and analyzed in scanning electron microscope (SEM) to enable us obtained the nature of the film formed on the steel surface. The characterization were performed at Department of Chemical Engineering, Ahmadu Bello University, Zaria, Nigeria using the scanning electron microscope (SEM of model no MVE016477830), Netherlands.

\section{RESULTS AND DISCUSSION}

Electrochemical impedance spectroscopy (EIS)

The electrochemical impedance spectroscopy was performed to investigate the effect of the inhibitor concentration on the impedance behavior of API 5L X-52 steel in $2 \mathrm{M} \mathrm{HCl}$ solution. The Nyquist and the corresponding bode plots are presented in Figure 2. In the Nyquist plot, because of the charge transfer resistance, a semicircle in each curve stands for a constant time. Increasing the concentration of metolazone drug increases the diameter of the circle from 50 to $500 \mathrm{mg} / \mathrm{L}$, which suggests an increase in the inhibitory effect. The inhibition efficiency based on impedance study can be calculated using the following eq. (1). 
$\mathrm{IE} \%=1-\frac{\mathrm{R}_{c t}(b l)}{R_{c t}(i n h)} \times 100$

where $R_{c t(b l)}$ is the charge transfer for the blank solution and $R_{c t(i n h)}$ is for inhibited solution. The inhibition efficiency is improved by expanding the concentration of metolazone with the highest value of $92.7 \%$ at $500 \mathrm{mg} / \mathrm{L}$. This increment in $R_{\mathrm{ct}}$ value is attributed to the development of a defensive film on the surface of the steel. The changes in $R_{c t}$ and CPE values were caused by the substitution of water molecules by adsorption of inhibitor on the carbon steel surface. The impedance profile in inhibited and uninhibited solution showed positive inflections at lower frequencies. The peaks in Bode plots are described as distinct and phase angle peaks shifted towards higher values of concentration of the inhibitor. Such is characteristic of adsorption processes occurring. Also in the Bode plot, the curves for all concentrations show single wave, which confirmed the one-time constant acquired by the Nyquist plot. According to the literature, if the phase angle equals $90^{\circ}$ or $0^{\circ}$, the electrochemical behavior at the steel solution interface is capacitive or resistive, respectively. The Bode plot in Figure 2 shows the existence of an equivalent circuit that contains a single constant phase element (CPE) in the metal/solution interface. The increment of absolute impedance at low frequencies in Bode plots confirms the fact that the protective effect of the inhibitors is concentration dependent in acid solution. Phase angle plots Figure 2 at all concentrations show one time constant, which is related to the charge transfer process [14-17]. Equivalent circuit model (Figure 2c) was used to model the impedance data. The circuit consist of solution resistance $\left(R_{s}\right)$, adsorption resistance $\left(R_{a}\right)$ and adsorption constant phase element represented by $Q_{a}$, charge transfer resistance $\left(R_{c t}\right)$ and constant phase double layer $\left(\mathrm{Q}_{\mathrm{dl}}\right)$, the data of these parameters are presented in Table 1 . The frequency of the constant phase element relied on the elements that connect the surface heterogeneities and the double layer capacitor at the metal-electrolyte interface ['18-19]. The constant phase element impedance CPE is express using eq. (2).

$Z_{C P E}=\left(Y_{o}(j \omega)^{n}\right)^{-1}$

where the amplitude of CPE is $Y_{o}$ and its imaginary units is $(j=\sqrt{ }-1$, the angular frequency $\omega$ and $\mathrm{n}$ is CPE power $(0<n \leq 1)$. It is seen in Table 1 that addition of inhibitors to the acidic medium, increases the $\mathrm{R}_{\mathrm{ct}}$ values with corresponding decreased in $\mathrm{Q}_{\mathrm{dl}}$ and $\mathrm{Q}_{\mathrm{a}}$ values, this is due to the increased in the thickness of the electric double layer containing the adsorption of the inhibitors molecules at the carbon steel surface. A good fit was obtained by fitting the equivalent circuit to explained the experimental data as shown in Table 1 as proven by the correlation parameter $\chi^{2}$.

\section{Polarization measurements}

Potentiodynamic polarization method was also carried out to study the effect of the temperature and inhibitor concentration on the polarization behavior of API 5L X-52 steel in 2 $\mathrm{M} \mathrm{HCl}$ solution without and with different concentrations of the metolazone drug. The experiments were conducted at different temperatures (303-323 K) (Figure 3). All the important electrochemical parameters derived from Tafel plots such as the corrosion potential $\left(\mathrm{E}_{\text {corr }}\right)$, corrosion current density $\left(\mathrm{i}_{\text {corr }}\right)$, corrosion rate $(\mathrm{CR})$, anodic Tafel slopes $(\beta \mathrm{a})$, cathodic Tafel slopes $(\beta c)$, and inhibition efficiency (IE \%) are summarized in Table 2, exception of inhibition efficiency (IE \%) that increases, other parameters values decreases as the concentration of metolazone increases. The anodic, cathodic Tafel slopes $(\beta \mathrm{a}$ and $\beta \mathrm{c})$, and the corrosion current density $i_{\text {corr }}$ were obtained from the extrapolation of anodic and cathodic Tafel lines to the corrosion potential. 
Table 1. EIS component values for API 5L X-52 steel in $2 \mathrm{M} \mathrm{HCl}$ solution with and without inhibitor.

\begin{tabular}{|c|c|c|c|c|c|c|c|c|c|}
\hline \multicolumn{6}{|c|}{$\mathrm{Q}_{\mathrm{dl}}$} & \multicolumn{4}{|c|}{$\mathrm{Q}_{\mathrm{a}}$} \\
\hline System & & $R_{c t}(\Omega$ & $\left(\mathrm{cm}^{2}\right)$ & $\mathrm{Y}_{0}$ & & $R_{a}\left(\Omega \mathrm{cm}^{2}\right)$ & $Y_{0}$ & $\mathrm{n}_{\mathrm{a}}$ & \multirow{2}{*}{$\chi^{2}$} \\
\hline $\mathrm{HCl} / \mathrm{ppm}$ & $\mathrm{R}_{\mathrm{s}}\left(\Omega \mathrm{cm}^{2}\right)$ & & IE\% & $\mathrm{S} \mathrm{s}^{\mathrm{n}} \mathrm{cm}^{2}$ & $\mathrm{n}_{\mathrm{dl}}$ & & $\mathrm{S} \mathrm{s}^{\mathrm{n}} \mathrm{cm}^{2}$ & & \\
\hline Blank & 0.32 & 19.24 & & $19 \times 10^{-4}$ & 0.728 & 0.09 & $28 \times 10^{-5}$ & 0.999 & $1.16 \times 10^{-4}$ \\
\hline 50 & 0.49 & 24.93 & 23 & $10.9 \times 10^{-4}$ & 0.653 & 1.62 & $12 \times 10^{-5}$ & 0.989 & $1.92 \times 10^{-4}$ \\
\hline 100 & 0.54 & 33.43 & 42 & $8.4 \times 10^{-4}$ & 1.220 & 2.48 & $9 \times 10^{-5}$ & 0.999 & $2.51 \times 10^{-4}$ \\
\hline 200 & 0.51 & 71.68 & 73 & $6.9 \times 10^{-4}$ & 0.890 & 2.22 & $8 \times 10^{-5}$ & 0.999 & $4.22 \times 10^{-4}$ \\
\hline 300 & 0.56 & 123.4 & 84 & $6.1 \times 10^{-4}$ & 0.994 & 3.61 & $7 \times 10^{-5}$ & 0.988 & $5.12 \times 10^{-4}$ \\
\hline 500 & 0.63 & 266.7 & 93 & $5.88 \times 10^{-4}$ & 0.998 & 3.88 & $6 \times 10^{-5}$ & 0.998 & $6.35 \times 10^{-4}$ \\
\hline
\end{tabular}

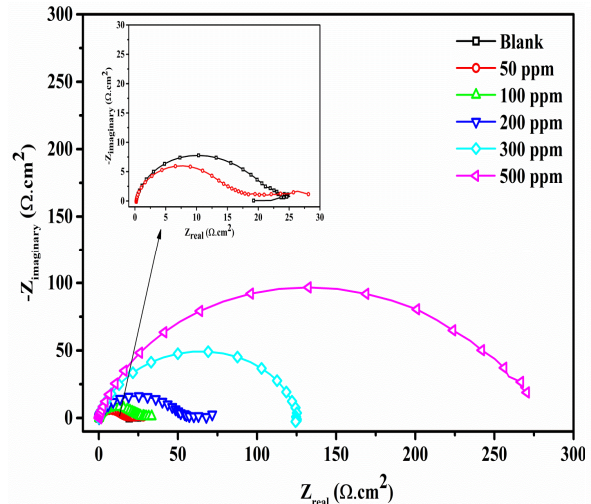

(a)

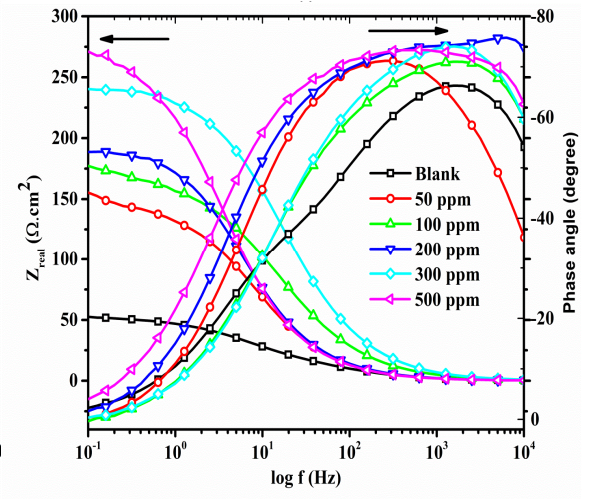

(b)

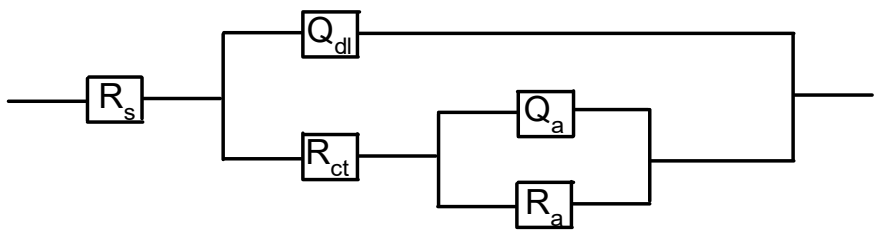

(c)

Figure 2. (a) Nyquist plot, (b) Bode plot and phase angle plot in absence and presence of different metolazone concentrations in $2 \mathrm{M} \mathrm{HCl}$ and (c) equivalent circuit model.

It is clearly seen in Figure 3 that addition of the metolazone leads to the inhibition of both cathodic and anodic reactions in all the study temperature. This supports the fact that the metolazone inhibits API 5L X-52 steel corrosion by controlling both anodic and cathodic reactions (mixed-type inhibitor), but predominantly at the anodic sites, this is because the maximum shift in the $E_{\text {corr }}$ with respect to the blank solution was within $85 \mathrm{mV}$ [20-21]. However, the negative displacement of the corrosion potentials, observed may be explained by the adsorption of the inhibitor molecules on active sites, thereby reducing the reduction of hydrogen ion $\left(\mathrm{H}^{+}\right)$and loss of electrons from the steel surface. The covering of adsorbed inhibitor molecules on the carbon steel surface decreases the dissolution of the carbon steel leading to increase in inhibition efficiency calculated by using eq. (3). 
$\% I E=\frac{i_{\text {corr }}(\text { blank })-i_{\text {corr }}(\text { inh })}{i_{\text {corr }}(\text { blank })} \times 100$

where $I_{\text {corr }}$ (blank) and $I_{\text {corr }}($ inh) represent the corrosion current density of blank and inhibited solutions respectively [15].

Table 2. Polarization data for API 5L X-52 steel in $2 \mathrm{M}$ hydrochloric acid in different temperature.

\begin{tabular}{|c|c|c|c|c|c|c|c|}
\hline Conc.(ppm) & $\begin{array}{l}E_{\text {corr }}(\mathrm{mV} \\
\text { vs. SCE })\end{array}$ & $\beta_{\mathrm{a}}(\mathrm{mV} / \mathrm{dec})$ & $\beta_{\mathrm{b}}(\mathrm{mV} / \mathrm{dec})$ & $I_{\text {corr }} \mu \mathrm{Acm}^{-2}$ & CR(mpy) & $\theta$ & $\% I E$ \\
\hline Temperature & \multicolumn{7}{|c|}{$303 \mathrm{~K}$} \\
\hline Blank & -446 & 102 & 454 & 560 & 256 & & \\
\hline 50 & -436 & 88 & 165 & 397 & 182 & 0.291 & 29.1 \\
\hline 100 & -447 & 88 & 150 & 334 & 152 & 0.403 & 40.3 \\
\hline 200 & -430 & 67 & 101 & 269 & 123 & 0.519 & 51.9 \\
\hline 300 & -445 & 61 & 91 & 101 & 46 & 0.819 & 81.9 \\
\hline 500 & -498 & 46 & 116 & 52.7 & 24 & 0.907 & 90.7 \\
\hline Temperature & \multicolumn{7}{|c|}{$313 \mathrm{~K}$} \\
\hline Blank & -316 & 39 & 323 & 1830 & 837 & & \\
\hline 50 & -436 & 80 & 86 & 543 & 240 & 0.703 & 70.3 \\
\hline 100 & -435 & 74 & 79 & 482 & 209 & 0.737 & 73.7 \\
\hline 200 & -438 & 69 & 66 & 434 & 185 & 0.763 & 76.2 \\
\hline 300 & -441 & 64 & 61 & 413 & 170 & 0.774 & 77.4 \\
\hline 500 & -443 & 59 & 57 & 349 & 164 & 0.809 & 80.9 \\
\hline Temperature & \multicolumn{7}{|c|}{$323 \mathrm{~K}$} \\
\hline Blank & -442 & 116 & 217 & 3560 & 1626 & & \\
\hline 50 & -308 & 38 & 300 & 2480 & 1132 & 0.303 & 30.3 \\
\hline 100 & -381 & 85 & 679 & 1710 & 781 & 0.520 & 53.0 \\
\hline 200 & -361 & 73 & 197 & 1500 & 686 & 0.579 & 57.9 \\
\hline 300 & -399 & 76 & 109 & 676 & 309 & 0.810 & 81.0 \\
\hline 500 & -409 & 72 & 100 & 347 & 158 & 0.903 & 90.3 \\
\hline
\end{tabular}

\section{Thermodynamic considerations}

The temperature effect on the corrosion behavior of API 5LX-52 steel in aqueous environment was examine at the temperature range 303 to $323 \mathrm{~K}$ using the results of potentiodynamic polarization techniques. The Activation energy, enthalpy change and change in entropy were used to illustrate the dependency of temperature on corrosion current density [22-25]. This parameters where all calculated using Arrhenius equation represented as eq. (4) and Eyring transition state equation (eq. 5) where $I_{\text {corr }}$ is the corrosion current density, $A$ is the exponential factor, $R$ is the universal gas constant, $N$ is the Avogadro's number and $h$ is Planks constant [19-21].

$\log I_{\text {corr }}=\log A-\frac{E a}{2.303 R T}$

$I_{\text {corr }}=\frac{R T}{N h} \exp \left(\frac{\Delta S_{a}^{o}}{R}\right) \exp \left(\frac{\Delta H_{a}^{o}}{R T}\right)$ 
TEMP (a) $303 \mathrm{~K}$

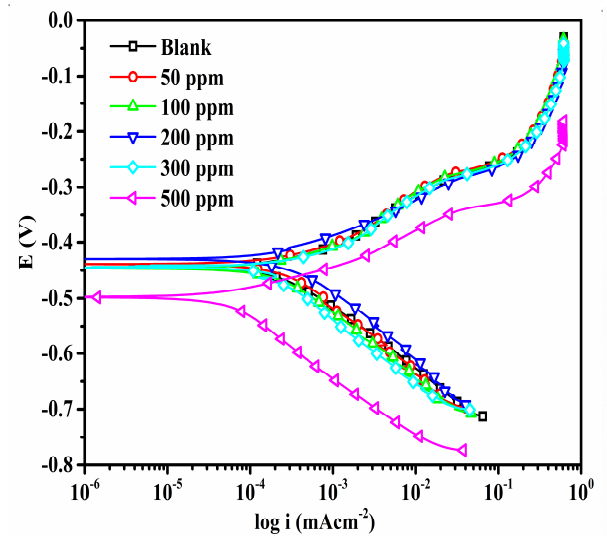

TEMP (b) $313 \mathrm{~K}$

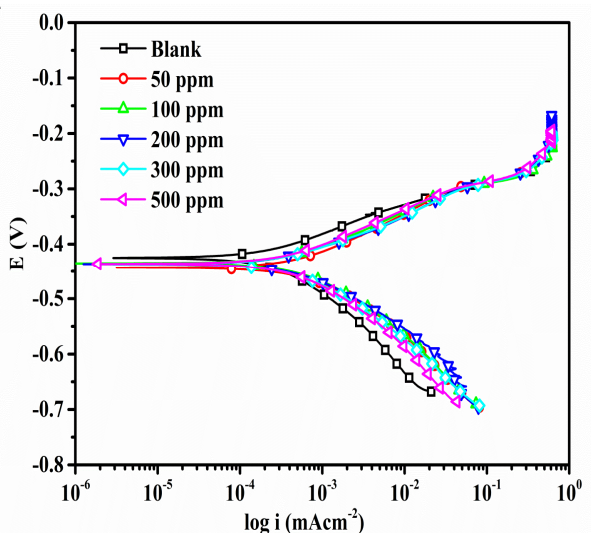

TEMP (c) $323 \mathrm{~K}$

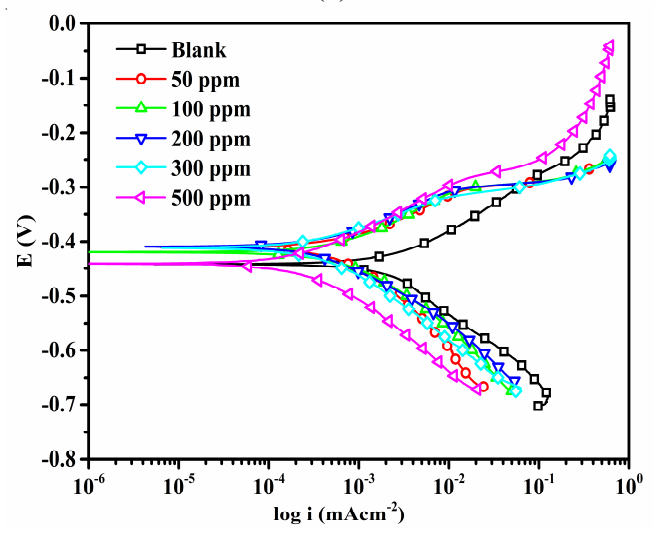

Figure 3. Polarization measurement of API 5L X-52 steel in $2 \mathrm{M} \mathrm{HCl}$ at different concentrations and temperatures.

A plot of $\log I_{\text {corr }}$ against $\frac{1}{T}$ gives a linear plot with slope $\frac{-E a}{2.303 R}$ shown in Figure 4a, while the plot of $\frac{\log I \text { corr }}{T}$ versus $\frac{1}{T}$ shown in Figure $4 \mathrm{~b}$ produced a straight line with slope $\frac{-\Delta H}{2.303 R}$ and intercept of $\log \frac{R}{N h}+\frac{\Delta S}{2.303 R}$, from which $\Delta H$ and $\Delta S$ were evaluated and presented in Table 3 . The results of Table 3 illustrates that the values of activation energy $\left(E_{a}\right)$ of the blank solution is higher than that of the inhibited solution. This behavior is an indication that metolazone posses the characteristics features of chemical adsorption on the metal surface [26].

The positive values of $\Delta \mathrm{H}$ listed in Table 3 show evidence of the endothermic nature of corrosion reaction of the metal suggesting a reduction in steel dissolution rate in the presence of metolazone. The values of entropy of adsorption are large positive values indicating the presence of disorderliness. Since their values are greater than zero $(\Delta S>0)$, it confirms that the reaction mechanism is feasible and spontaneous [26]. 


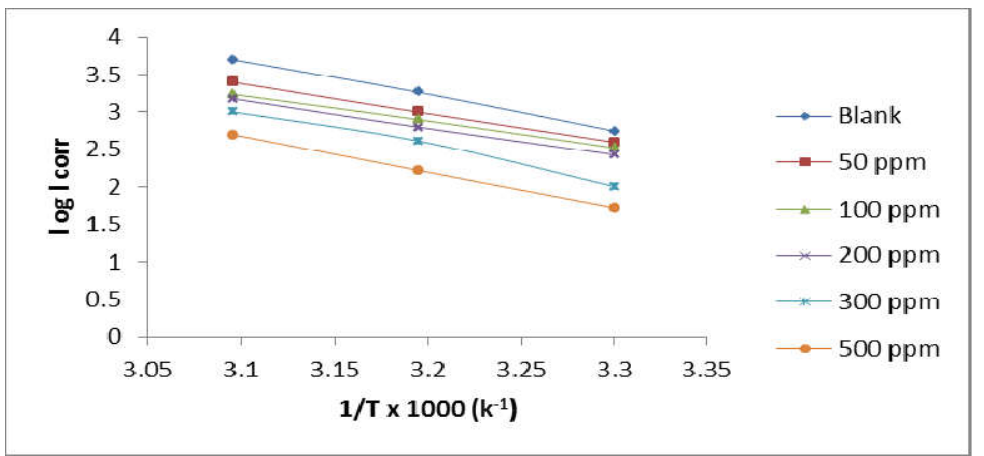

Figure 4a. Arrhenius plots of $\log I_{\text {corr }}$ against 1/T for the studied steel in $2 \mathrm{M} \mathrm{HCl}$ in the absence and presence of metolazone.

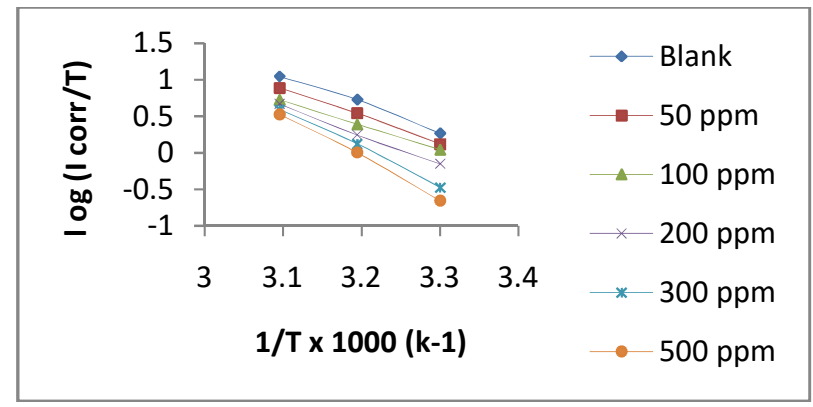

Figure 4b. Eyring's transition state equation of plot of $\frac{\log \text { Icorr }}{T}$ against $1 /$ T for studied steel in 2 $\mathrm{M} \mathrm{HCl}$ in the absence and presence of metolazone.

Table 3. Thermodynamic parameters for API $5 \mathrm{~L} \mathrm{X-52} \mathrm{steel} \mathrm{in} 2 \mathrm{M} \mathrm{HCl}$ solution in the presence and absence of metolazone.

\begin{tabular}{|c|c|c|c|c|c|c|}
\hline Conc $(\mathrm{ppm})$ & $\mathrm{Ea}(\mathrm{kJ} / \mathrm{mol})$ & $\mathrm{R}^{2}$ & $\Delta \mathrm{H}(\mathrm{kJ} / \mathrm{mol})$ & $\mathrm{R}^{2}$ & $\Delta \mathrm{S}(\mathrm{J} / \mathrm{mol} / \mathrm{K})$ & Slope \\
\hline Blank & 89 & 0.999 & 73 & 0.992 & 245 & -3.8 \\
\hline 50 & 75 & 0.999 & 72 & 0.998 & 234 & -3.8 \\
\hline 100 & 66 & 0.999 & 64 & 0.999 & 211 & -3.3 \\
\hline 200 & 63 & 0.999 & 76 & 0.998 & 249 & -4.0 \\
\hline 300 & 62 & 0.987 & 100 & 0.997 & 321 & -5.2 \\
\hline 500 & 72 & 0.999 & 110 & 0.997 & 352 & -5.8 \\
\hline
\end{tabular}

\section{Adsorption consideration}

Adsorption isotherm also provides important information about the interaction between the inhibitor and metal surface. The experimental data were applied to various adsorption models to obtain the best fit. The experimental data were found to fit the Langmuir isotherm (Figure 5) according the eq. (6).

$\log C / \theta=\frac{1}{K_{a d s}}+\log C$

where $\mathrm{C}$ is the concentration of inhibitor, $\theta$ is the degree of surface coverage and $\mathrm{K}_{\mathrm{ads}}$ is the equilibrium constant of the adsorption process. The free energy $\Delta \mathrm{G}_{\mathrm{ads}}$ adsorption of metolazone 
on the surface of the steel was calculated using the intercept of Figure 5 regarded as the equilibrium constant and substituted into eq. 7.

$K_{a d s}=1 / 55.5 \exp \left(-\Delta G_{a d s} /_{R T}\right)$

The results of $\Delta \mathrm{G}_{\mathrm{ads}}$ listed in Table 4 shows negative values supporting a spontaneous reaction which was earlier proposed [27-30].

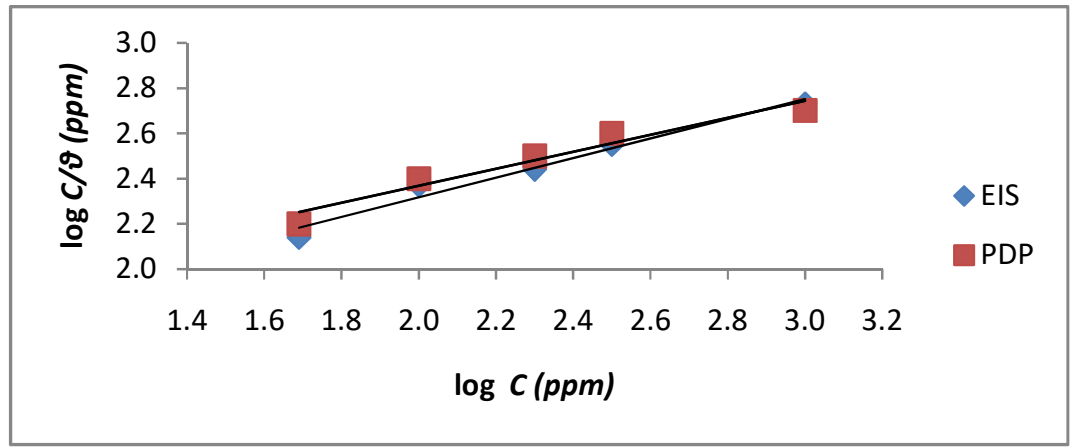

Figure 5. Plots of Langmuir adsorption isotherm for metolazone on the studied steel surface at $303 \mathrm{~K}$.

\section{Scanning electron microscope}

Figure 6 shows the surface morphology of Fresh steel (a), steel in the inhibited solution of 500 $\mathrm{mg} / \mathrm{L}$ metolazone (b) and the uninhibited solution (c) at $303 \mathrm{~K}$. The images of the API 5L X-52 steel surface in $2 \mathrm{M} \mathrm{HCl}$ solution Figure (6c) appears severely damage. However, in the presence of metolazone drugs Figure $6 \mathrm{~b}$, surface morphology of API 5L X-52 steel is remarkably improved. This observation further supports the protection of API 5L X-52 steel by adsorption of metolazone [31-37]. These results agreed with the inhibition efficiency obtained from the electrochemical measurement.

Table 4. Adsorption free energy values of metolazone on API 5L X-52 steel.

\begin{tabular}{|c|c|c|c|c|}
\hline Methods & $\Delta \mathrm{G}_{\mathrm{ads}} \mathrm{J} / \mathrm{mol} / \mathrm{K}$ & Slope & $\mathrm{K}_{\mathrm{ads}}$ & $\mathrm{R}^{2}$ \\
\hline EIS & -14.6 & 0.432 & 1.442 & 0.971 \\
\hline Tafel & -16.3 & 0.375 & 1.610 & 0.946 \\
\hline
\end{tabular}

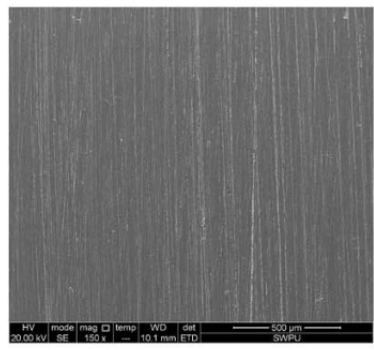

(a)

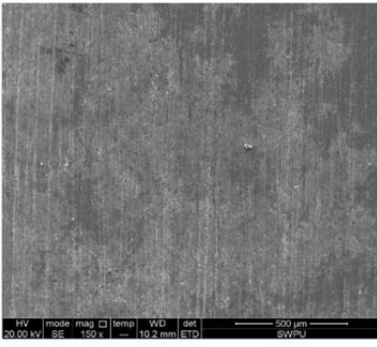

(b)

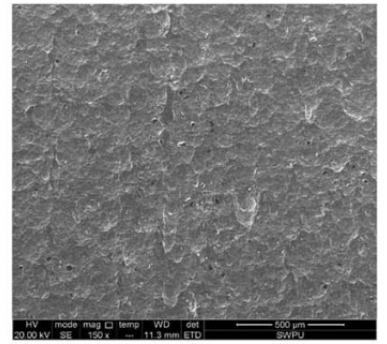

(c)

Figure 6. (a) Image of polished carbon steel surface before, (b) image of polished carbon steel surface with METO and (c) image of polished carbon steel in $2 \mathrm{M} \mathrm{HCl}$ solution. 


\section{CONCLUSION}

From the experimental data and discussion of the present investigation, we can conclude that: metolazone drug showed good inhibition efficiency for API 5L X-52 steel in $2 \mathrm{M} \mathrm{HCl}$ solutions. The inhibition efficiency increases with the increase in concentration and increases with the increase in temperature. PDP results indicate that the presence of metolazone drug decreases both the rate of anodic and cathodic API 5L X-52 steel dissolution, and acts as a mixed type inhibitor. The adsorption of inhibitor molecules on the API 5L X-52 steel surface obeys Langmuir adsorption isotherm. Scanning electron Microscopy SEM revealed the presence of a protective film of the inhibitor on the API 5L X-52 steel surfaces. The results obtained from EIS and PDP were in good conformity.

\section{ACKNOWLEDGEMENT}

Magdalene Edet Ikpi is grateful to the China-Africa Science and Technology Partnership Program (CASTEP) for the 2012 Award for Equipment Donation Support from which the experimental analysis of this research was made possible.

\section{REFERENCES}

1. Chahul, H.F.; Ndukwe, G.I.; Ogwu, D.O. Thermodynamic study on the kinectics of acid dissolution of aluminium in the presence of Napoleonaea imperialis seeds extract and iodideion. Ovid. Univ. Annal. Chem. 2018, 29, 103-109.

2. Raghavendra, N. Application of expired alprazolam drug as corrosion inhibitor foraluminum in $3 \mathrm{M} \mathrm{HCl}$ environment. J. Sci. Eng. Technol. 2018, 6, 35-42.

3. Okafor, P.C.; Ebenso, E.E.; Ekpe, U.J. Azadirachta indica extracts as corrosion inhibitor for mild steel in acid medium. Int. J. Electrochem. Sci. 2010, 5, 978-993.

4. Eddy, N.O.; Odoemelam, S.A.; Ogoko, E.C.; Ita, B.I. Inhibition of the corrosion of zinc in 0.01-0.04 $\mathrm{M} \mathrm{H}_{2} \mathrm{SO}_{4}$ by erythromycin. Port. Electrochim. Acta 2010, 28, 15-26.

5. Fouda, A.S.; El-Haddad, M.N.; Abdallah, Y.M. Septazole: Antibacterial drug as green corrosion inhibitor for copper in hydrochloric solution. Int. J. Innov. Res. Sci. Eng. Technol. 2013, 2, 7073-7085.

6. Attia, M.A.; Gamal, A.E.; Hamad, A.A.; Sami, A.A. Corrosion inhibition of mild steel in acid medium by magnetite myrrh nanocomposite. Int. J. Electrochem. Sci. 2014, 9, 84468457.

7. Naqvi, I.; Saleemi, A.R.; Naveed, S. Cefixime: A drug as efficient corrosion inhibitor formild steel in acidic media: Electrochemical thermodynamic studies. Int. J. Electrochem. Sci. 2011, 6, 146-161.

8. Baby, N.; Manjula, P.; Mainmegalai, S. Azole drug: A novel inhibitor for corrosion. Res. J. Chem. Sci. 2015, 5, 11-16.

9. Ade, S.B.; Shitole, N.V.; Lonkar, S.M. Antifungal drugs used as metal corrosion inhibitor in various acid medium. Int. J. Chem. Technol. Res. 2014, 6, 3642-3650.

10. Karthikeyan, S.; Jeeva, P.A.; Raja, K. Experimental studies of an antibacterial agent on the corrosion of mild steel in $1 \mathrm{M} \mathrm{H}_{2} \mathrm{SO}_{4}$. J. Chem. Pharm. Res. 2015, 7, 906-912.

11. Abdullatef, O.A. Chemical and electrochemical studies on the corrosion of mildsteel, copper and zinc in $0.5 \mathrm{M} \mathrm{H}_{2} \mathrm{SO}_{4}$ solution in presence of azithromycin as effective corrosion inhibitor. $J$. Adv. Chem. 2015, 11, 3642- 3655.

12. ASTM Sec, Spec 5L specification for pipe Line, Vol. 8, 14th ed., West Conshohoken: Pennsylvania; 2013.

13. Yang, H.; Zhang, M.; Singh, A. Investigation of inhibition effect of ketoconazoleon mild steel corrosion in hydrochloric acid. Int. J. Electrochem. Sci. 2018, 13, 9131-9144. 
14. Nkem, B.I.; Akens, H.A. Inhibition and Adsorption of oil extract of Balanites aegyptiaca seeds on the corrosion of mild steel in hydrochloric acid environment. World Sci. News 2019, 183-197.

15. Abeng, F.E.; Ikpi, M.E.; Uwakwe, K.; Ikpi, G. Corrosion inhibition and adsorption characteristics of API 5L X-52 steel by antibiotic drug in $\mathrm{HCl}$ solution. Int. Res. J. Pure Appl. Chem. 2017, 15, 1-12.

16. Abeng, F.E.; Ekpe, U.J.; Ikeuba, A.I.; Ugi, B.U.; Nna, P.J. Inhibitive action of alkaloid and non-alkaloid fractions of the ethanolic extracts of Phyllanthus amarus on the corrosion of mild steel in $\mathrm{HCl}$ solution. Globle J. Pure Appl. Sci. 2013, 19, 107-117.

17. Ugi, B.U; Abeng, F.E. Corrosion inhibition effects and adsorption characteristics of ethanol extract of king bitter root (Andrographis paniculata) on mild steel in $1.0 \mathrm{M} \mathrm{HCl}$ and $\mathrm{H}_{2} \mathrm{SO}_{4}$ acid media. Fountain J. Nat. Appl. Sci. 2013, 2, 10-21.

18. El Issami, S.; Bazzi, L.; Mihit, M.; Hammouti, B.; Kertit, S.; Ait Addi, E.; Salghi, R. Triazolic compounds as corrosion inhibitors for copper in hydrochloric acid. Pig. Res. Technol. 2007, 36, 161-168.

19. Abeng, F.E.; Idim, V.D.; Nna, P.J. Kinetic and thermodynamic studies of corrosion inhibition of mild steel using methanolic extract of Erigeron floribundus (Kunth) in $2 \mathrm{M}$ $\mathrm{HCl}$ solution. World News Nat. Sci. 2017, 10, 26- 38.

20. Ikpi, M.E.; Abeng, F.E.; Okonkwu B.O. Experimental and computational study of levofloxacin as corrosion inhibitor for carbon steel in acidic media. World News Nat. Sci. 2017, 9, 79-90.

21. Fouda, A.S.; Bekheit, G.E.; El-sherbari, M.W. Corrosion inhibition of aluminnum silicon alloy in hydrochloric acid solutions using carbamide thioanhydride derivatives. J. Bio. Tribo. Corros. 2016. DOI: 10.1007/s40735-016-0039-y.

22. Okafor, P.C.; Ikpi, M.E.; Uwah, I.E.; Ebenso, E.E.; Ekpe, U.J.; Umoren, S.A. Inhibitory action of Phyllanthus amarus extracts on the corrosion of mild steel in acidic. Corr. Sci. 2008, 50, 2310-2317.

23. Obot, I.B.; Umoren, S.A.; Egbedi, N.O. Corrosion inhibition and adsorption behaviour for aluminum by extract of Aningeria robusta in $\mathrm{HCl}$ solution: Synergistic effect of iodide ions. J. Mater. Envir. Sci. 2011, 2, 60-71.

24. Ugi, B.U.; Abeng, F.E.; Obeten, M.E.; Uwah, I.E. Management of aqueous corrosion of federated mild steel (local constructional steel) at elevated temperature employing environmentally friendly inhibitors: Matriccaria chamomilla plant. Int. J. Chem. Sci. 2019, 3, 6-12.

25. Fadare, O.O.; Okoronkwo, A.E.; Olasehinde, E.F. Assessment of anticorrosion potential of extract Ficus aspertoliamiq (Moraceae) on mild steel in acidic medium. Afr. J. Pure Appl. Chem. 2016, 10, 8-22.

25. Gassama, D.; Diagne, A.A.; Yade, I.; Fall, M.; Faty, S. Investigations on the corrosion of constructional steels in different aqueous and simulated atmospheric environments. Bull. Chem. Soc. Ethiop. 2015, 29, 299-310.

26. Bader, A.; Shaheen, U.; Aborehab, M.A.S.; El Ouadi, Y.; Bouyanzer, A.; Hammouti, B.; Ben Hadda, T. Inhibitory effect of Acacia hamulosa methanol extract on the corrosion of mild steel in $1 \mathrm{M} \mathrm{HCl}$ acid. Bull. Chem. Soc. Ethiop. 2018, 32, 323-335.

27. Eddy, A. Inhibition of corrosion of zinc $0.01 \mathrm{M} \mathrm{H}_{2} \mathrm{SO}_{4}$ by amino-1 cylopropyl -7[(3R5S 3,5dimethylpiperazin-1-yl)-6,8-difloro-4-oxo quinoline-3-carboxlic acid. J. Corr. Sci. Eng. 2007, 10, $1466-8858$.

28. Ikpi, M.E.; Abeng, F.E. Electrochemical impedance spectroscopy and gravimetric study of the corrosion inhibition of API $5 \mathrm{~L} \mathrm{X-52} \mathrm{steel} \mathrm{in} \mathrm{HCl}$ medium by levofloxacin. Int. J. Sci. Res. 2017, 6, 623- 628. 
29. Umoren, S.A.; Obot, E.E.; Ebenso, E.E.; Okafor, P.C.; Ogbobe, O.; Oguzie, E.E. Gum arabic as potential corrosion inhibitor for aluminium in alkaline medium and its adsorption characteristics. Anti-corr. Meth. Mat. 2006, 53, 277-282.

30. Ogoko, E.C.; Ogunsipe, A. Inhibitive effect of dirithromycin on the corrosion of zinc in $\mathrm{H}_{2} \mathrm{SO}_{4}$. Chem. Sci. Trans. 2015, 4, 503-515.

31. Mayakrishnan, G.; Pitchai, S.; Raman, K.; Ramani, A.; Nagarajan, S. Inhibitive action of Clematis gouriana extract on the corrosion of mild steel in acidic medium. Ionics 2011, 17, 843-852.

32. Wang, D.; Li, Y.; Zhang, L. Experimental and theoretical research on a new corrosion inhibitor for effective oil and gas acidification, RSC Adv. 2019, 9, 26464-26475.

33. Gassama, D.; Diagne, A.A.; Yade, I.; Fall, M.; Faty, S. Investigations on the corrosion ofconstructional steels in different aqueous and simulated atmospheric environments. Bull. Chem. Soc. Ethiop. 2015, 29, 299-310.

34. Dhaundiyal, P.; Bashir, S.; Sharma, V.; Kumar, A. An investigation on mitigation ofcorrosion of mild steel by Origanum vulgare in acidic medium, Bull. Chem. Soc. Ethiop. 2019, 33, 159-168.

35. Onukwuli, O.D.; Anadebe, V.C.; Okafor, C.S. Optimum prediction for inhibition efficiency of Sapium ellipticum leaf extract as corrosion inhibitor of aluminium alloy (AA3003) in hydrochloric acid solution using electrochemical impedance spectroscopy and response surface methodology. Bull. Chem. Soc. Ethiop. 2020, 34, 175-191.

36. Obot, I.B.; Madhankumar, A.; Umoren, S.A.; Gasem. Z.M. Surface protection of mild steel using benzimidazole derivatives: Experimental and theoretical approach, J. Adhes. Sci. Technol. 2015. DOI: http://dx.doi.org/10.1080/01694243.2015.1058544.

37. Abeng, F.E.; Anadebe, V.C; Idim, V.D.; Edim, M.M. Anti-corrosion behaviour of expired tobramycin drug on carbon steel in acidic medium. South Afr. J. Chem. 2020, 73, 125-130. 